\title{
VALOR DAS EMPRESAS, CUSTO DE CAPITAL E A COMPETITIVIDADE DAS NAÇÕES: A LOCALIZAÇÃO É IMPORTANTE?**
}

\author{
COMPANY VALUE, COST OF CAPITAL AND COMPETITIVENESS \\ OF NATIONS: DOES LOCATION MATTER?
}

\author{
MARTIM FRANCISCO DE OLIVEIRA E SILVA \\ Doutorando em Administração de Empresas \\ no Instituto de Administração e Gerência \\ da Pontifícia Universidade Católica do Rio de Janeiro - RJ \\ E-mail:martim.francisco@uol.com.br \\ LUIZ FELIPE JACQUES DA MOTTA \\ Professor Doutor do Instituto de Administração e Gerência \\ da Pontifícia Universidade Católica do Rio de Janeiro - RJ \\ E-mail: Ifelipe@iag.puc-rio.br
}

\section{RESUMO}

Identificar as variáveis que se associam ao valor das empresas e ao seu custo de capital é um assunto tão antigo como pouco esclarecido na administração. Este artigo busca verificar o relacionamento entre o ambiente dos países e o valor e o custo de capital das empresas neles localizados.

A pesquisa foi efetuada com o apoio dos dados anuais de competitividade dos países, que são produzidos pelo IMD (International Institute for Management Development) e os dados dos valores das empresas fornecidos pelo Morgan Stanley Capital International (MSCI). Os resultados indicaram a relevância do ambiente competitivo nacional para explicar as diferenças de valor entre as empresas e do custo de capital entre os países, sendo indicadas as importâncias relativas dos fatores de competitividade, de acordo com o estágio de desenvolvimento dos países considerados nุa amostra.

Palavras-chave: Valor das Empresas; Custo de Capital; Competitividade das Nações.

\section{ABSTRACT}

The identification of variables associated with companies' value and cost of capital is an old and still unclear issue in management. This article studies the relation between countries' environments and their companies' value and cost of capital. The research was carried out using annual data on the competitiveness of nations produced by the International Institute for Management Development (IMD), as well as company value data by Morgan Stanley Capital International (MSCI). The results show the importance of the nation's environment in explaining country differences in companies' value and cost of capital. The relative importance of different factors of competitiveness, according to the countries' stage of development is also shown.

Keywords: Value of companies; Cost of Capital; Competitiveness of Nations. 


\section{INTRODUÇÃO}

Por que algumas empresas alcançam o sucesso e outras não? Por que o custo de capital para as empresas difere tanto entre os países? Essas questões intrigam há anos homens de negócio, acadêmicos, trabalhadores e os governos de diversas nações.

Com a difusão do Modelo das Cinco Forças Competitivas do Professor Porter (1980), a explicação sobre os fatores que condicionam a rentabilidade de uma Indústria encontrou um modelo teórico que explicaria porque o setor farmacêutico é, habitualmente, tão lucrativo em todo o mundo, enquanto o siderúrgico e o de transporte rodoviário, normalmente, obtêm taxas tão modestas para a rentabilidade sobre o capital investido.

Uma outra linha de pesquisa, na qual este artigo se apóia, busca associar o sucesso das empresas ao ambiente competitivo mais geral dos seus países, incluindo forças sociais, políticas e econômicas. Esse ambiente competitivo vem sendo avaliado por instituições internacionais como o IMD (International Institute for Management Development), sediado na Suíça, cujos dados dos Relatórios Anuais de 1997 até 2004, foram utilizados neste artigo.

O sucesso das empresas pode ser medido em termos de rentabilidade de longo prazo sobre o capital investido, a qual implica em um maior valor criado para os acionistas, por meio da valorização de suas ações. A literatura de finanças associa o valor das empresas, entre outros fatores, ao seu custo de capital, que também deve se relacionar às condições de seu ambiente competitivo, conceito que será, também, explorado neste trabalho.

Este artigo visa associar as características dos ambientes nacionais dos países ao valor e ao custo de capital de suas empresas. Ele inicia com uma revisão da literatura, seguida pela metodologia da pesquisa, baseada nos rankings de competitividade produzidos pelo IMD e nos dados relacionados aos valores das empresas de capital aberto em relação ao seu valor contábil em 44 países, oriundos da base de dados do Morgan Stanley Capital International (MSCI).

No Brasil desse início do século XXI, onde a preocupação com o reduzido crescimento econômico das últimas duas décadas, bem como com as desigualdades sociais são os principais temas nacionais, compreender os fatores que possibilitam o sucesso das empresas deve permitir o planejamento e a execução de políticas públicas e privadas mais efetivas. Logo, o tema é de interesse para administradores, analistas industriais, estrategistas e acadêmicos que queiram obter uma melhor compreensão dos fatores que influenciam os resultados econômicos das organizações, de maneira a otimizar as aplicações de recursos públicos e privados, bem como aumentar as chances de sucesso das empresas brasileiras.

\section{REVISÃO DA LITERATURA}

O valor de uma empresa é o valor presente dos fluxos de caixa gerados por ela, descontados do seu custo de capital (DAMODARAN, 2001), o qual reflete o custo médio ponderado do custo de oportunidade de seu capital próprio e das taxas de juros dos seus empréstimos e financiamentos. A identificação das variáveis que se relacionam com o valor de uma empresa é um tema antigo e ainda pouco esclarecido na administração. Ele está vinculado ao sucesso ou fracasso das organizações, à medida que os investidores não irão se conformar em manter uma alternativa de investimento com potencial de rentabilidade e valorização inferior ao que eles poderiam obter com outras empresas, o que estimularia um fluxo de capital para outras companhias. Diversos trabalhos tentaram explicar que fatores condicionam a rentabilidade de uma empresa, a qual se associa o seu valor para os seus acionistas, alguns descritos a seguir.

$\mathrm{Na}$ década de 80, Michael Porter, em seu livro "Competitive Strategy" (no Brasil, "Estratégia Competitiva: Técnicas para Análise de Indústrias e da Concorrência" - ver bibliografia), apresentou um modelo destinado a explicar os condicionantes da rentabilidade do capital investido em uma indústria. Se as cinco forças presentes em um setor industrial: entrantes potenciais, produtos substitutos, fornecedores, concorrentes e compradores, fossem favoráveis e equilibradas, a indústria teria um potencial de rentabilidade de longo prazo superior ao potencial médio de outras indústrias. Isso ocorreria porque as cinco forças seriam as variáveis que influenciariam os preços, custos e os níveis de investimento, ou seja, os elementos do retorno sobre o capital investido.

Em cada indústria, a existência de competidores atuando com estratégias semelhantes em determinadas dimensões, gerou o conceito de Grupos Estratégicos, que foi também explorado por Porter em 1980. Embora alguns grupos estratégicos em uma indústria apresentem resultados econômicos superiores aos dos demais, a questão de quais variáveis se relacionariam à rentabilidade de longo prazo das empresas individuais continuou sem solução.

A Visão Baseada em Recursos, que possui suas raízes mais próximas a partir dos estudos de Wernerfelt (1984), destaca que as empresas são um conjunto de recursos, que, sendo adequadamente explorados, permitem que sejam mais bem aproveitadas as oportunidades e neutralizadas as ameaças do meio ambiente, alcançando-se um desempenho superior aos dos competidores. Para serem uma fonte de vantagem competitiva, esses recursos precisariam atender a quatro condições: serem valiosos, raros, de difícil imitação e seu emprego ser suportado pela organização. Para alcançar uma performance competitiva superior à da concorrência, 
seria, então, necessário enfocar os ativos e habilidades que seriam a base de uma vantagem competitiva sustentável. Assim, as empresas deveriam desenvolver e manter seus recursos mais importantes, selecionando as estratégias que maximizassem o retorno desses recursos, neutralizando os ativos e habilidades de seus concorrentes.

Uma importante linha de pesquisa alternativa busca relacionar o valor das empresas ao seu ambiente mais geral, em especial aos de seus países de origem (BEIM, 2001). Entre essas pesquisas, há uma corrente acadêmica que tem procurado associações entre o ambiente legal e as finanças, mostrando que diferenças na legislação e na aplicação de leis nos países podem afetar a política de dividendos, a disponibilidade e o custo de capital, bem como as avaliações do mercado a respeito do valor das empresas (LA PORTA et al., 1997). Entre as leis que criam incentivos para uma maior valorização das empresas estão as associadas aos instrumentos de Governança Corporativa, que se relacionam a mais elevados valores Q-Tobin e a retornos sobre os ativos (KLAPPER, 2002). Outra variável associada à questão legal é o nível de corrupção presente em um país, que influencia, negativamente, o valor das suas empresas (LEE, 2002) e que se relaciona às religiões, à origem do sistema legal (LA PORTA et. al., 1999) ou ao estágio de desenvolvimento de uma nação (LEE, 2002).

A variável Q-Tobin, operacionalmente definida como o quociente entre o valor de mercado de uma empresa e o valor de reposição de seus ativos (TOBIN, 1969), foi, inicialmente, adotada para explicar e fundamentar decisões de investimento (JOSE, 1986), pois, quando ela superasse a unidade, as empresas possuiriam um incentivo para investir, uma vez que o novo capital investido tenderia a exceder o seu custo (LINDENBERG et al., 1981). A utilização dessa variável para medir a atratividade dos investimentos, induziu a sua utilização para medir os lucros extraordinários atribuíveis a monopólios industriais ou a fatores específicos das empresas individuais (SMIRLOCK et al., 1984; PETERAF, 1993, VILLALONGA, 2004). Assim, os setores da economia com Q-Tobin superiores a um, seriam aqueles que desfrutassem de um ambiente competitivo mais favorável, possuíssem produtos e fatores de produção relativamente únicos, contribuíssem para um desempenho acima da média em uma economia (SMIRLOCK et al., 1984, BARNEY, 1996).

A utilização do Q-Tobin para medir o desempenho das empresas em substituição a indicadores contábeis, como o retorno dos investimentos ou o retorno dos ativos, permite reduzir as distorções causadas pela legislação de impostos, convenções contábeis arbitrárias e condições eventualmente desequilibradas de rentabilidades de curto prazo (FISHER, 1983). Entretanto, uma das críticas ao Q-Tobin associa-se à inclusão do goodwill nas possíveis diferenças entre o valor de mercado e os correspondentes valores contábeis de contas do Ativo e Passivo. A utilização de Q-Tobin mostra a importância do uso do mercado de capitais para investigar questões de competitividade industrial e será utilizado, nesta pesquisa, a partir dos dados disponibilizados pelo MSCl.
Historicamente, as explicações relativas ao desempenho e à competitividade das nações abordavam a questão do comércio internacional.

A noção de vantagem absoluta foi descrita, em 1776 , por Adam Smith em: A Riqueza das Nações (SMITH, 2000), que identificou os quatro principais fatores de produção: terra, capital, recursos naturais e trabalho. Assim, uma nação exportaria produtos se ela fosse o produtor mundial de mais baixo custo. Guiados por interesses individuais, os recursos de uma nação seriam alocados em sua forma mais eficiente, resultando no bem-estar da população. Segundo Smith, esforços do Estado e das pessoas, por melhorias sociais, são menos efetivos do que as forças de mercado, por ele chamado de "Mão Invisível" (op. cit., 2000).

O conceito de Smith foi ampliado por Ricardo em 1817 (RICARDO, 1996), que enfatizou como os países deveriam competir, permitindo que as forças de mercado alocassem recursos nas indústrias que fossem relativamente mais produtivas. Dessa maneira, a especialização dos países participantes do comércio internacional permitiria a obtenção de vantagens devido ao intercâmbio de um conjunto de produtos e de seus benefícios. Os países que possuíssem abundância de alguns recursos poderiam explorar a sua vantagem comparativa quando produzissem produtos que utilizassem intensamente esses fatores. Assim, para uma mesma quantidade de trabalho, um país poderia obter uma maior quantidade de produtos por causa do comércio. Daí decorreria que a especialização significaria a potencialização da capacidade de produção e consumo de todas as nações, sendo, portanto um fator de desenvolvimento e de bem estar dos povos.

O reconhecimento da importância do ambiente mais geral para o desenvolvimento econômico foi destacado por autores como Marx (1976), que salientou a influência de fatores sócio-políticos e do capital. Quanto mais produtivo o capital, maior a expansão do uso de equipamentos e do uso da terra, aumentando-se as oportunidades de aumento de salários e da existência material dos trabalhadores.

A busca de relações entre valores, religião, cultura e o desempenho econômico das nações foi feita por autores como Max Weber (2001). Segundo ele, os valores do protestantismo voltados para o trabalho, busca da prosperidade $e$ a frugalidade, permitiriam a ascensão do capitalismo, e, em decorrência, o crescimento econômico e o desenvolvimento das nações.

O papel do empreendedorismo, da inovação e do avanço tecnológico como um fator de competitividade foi destacado por autores como Schumpeter (1984). Para ele, embora a maior atenção fosse dada aos mercados que tinham condições estáveis, a competição mais relevante ocorreria com os novos produtos, as novas tecnologias, as novas fontes de fornecimento ou o novo tipo de organização, que seja capaz de dominar uma vantagem de custo ou qualidade e seja mais efetiva.

O conceito de administração como um fator de competitividade foi explorado por autores como Sloan (1963), que ampliou o conceito de delegação de autoridade, a im- 
portância da estrutura corporativa e dos estilos gerenciais nas organizações industriais. A importância do trabalhador do conhecimento foi, inicialmente explorada por Drucker (1969), que ampliou esse conceito para diversas áreas das organizações capitalistas, destacando os novos papéis e responsabilidades gerenciais na economia. O conceito do conhecimento como fator de competitividade foi refinado por Negroponte (1995), que salientou o papel das tecnologias de informação e comunicação que podem ser transmitidas virtualmente de maneira instantânea, global e grátis, transformando-se em produtos e serviços.

As idéias anteriormente descritas foram integradas por Porter (1990), que propôs um modelo de competitividade das nações, chamado de "Diamante Competitivo". Segundo ele, os ambientes de algumas nações seriam mais apropriados para certas indústrias. Assim, de acordo com quatro variáveis presentes nos ambientes das nações que se inter-relacionariam: Condições dos fatores; Estratégia, estrutura e rivalidade; Condições da demanda e Indústrias relacionadas; determinados setores da economia possuiriam melhores condições de prosperidade e competitividade internacional, o que por sua vez levaria à melhoria da qualidade de vida e aumento da riqueza das nações.

Kogut (1991) examinou o conceito de competitividade dos países, a partir das diferenças observadas em suas capacitações tecnológicas e organizacionais, as quais influenciariam a performance das empresas localizadas nesses países. As diferenças entre os níveis de competitividade dos países seriam uma função da abertura relativa das fronteiras dos países em relação à abertura de suas empresas para novas tecnologias e capacitações gerenciais.

No entanto, na atualidade, o conceito de competitividade ainda não dispõe de uma definição amplamente aceita. Para as empresas, a competitividade representa a capacidade de competir em mercados internacionais com uma estratégia global. Para os políticos, a competitividade significa uma balança comercial favorável. Para os economistas, significa um baixo custo unitário da mão-de-obra, ajustado pelas taxas de câmbio (PORTER, 1990).

Para o WEF - World Economic Fórum (2000), a competitividade das nações depende não apenas da capacidade de alcançar elevadas taxas de crescimento de maneira sustentável, mas também da habilidade que as economias nacionais possuem em melhorar as tecnologias, tanto através da inovação em seus países, como por meio da adoção rápida e ampla de tecnologias desenvolvidas no exterior.

De acordo com o IMD, a competitividade das nações é um campo do conhecimento econômico que analisa os fatos e políticas que influenciam a capacidade de uma nação criar e manter um ambiente que sustente uma maior criação de valor pelas suas empresas e mais prosperidade para as suas populações. A Competitividade de uma Nação poderia ser medida através de variáveis como: o Desempenho da Economia, Eficiência Governamental, Ambiente de Negócios e Infra-estrutura (IMD, 2004). Essas variáveis serão mais detalhadas na seção seguinte. Assim, os ambientes mais dinâmicos permitiriam uma melhoria da competitividade das empresas, e, em decorrência, um aumento, tanto no seu valor, quanto na qualidade de vida da sua população (PORTER, 1990).

O custo de capital possui uma forte associação com o valor das empresas, uma vez que esse pode ser obtido por meio do desconto de fluxos futuros de caixa por uma taxa que representa um custo médio ponderado das fontes de capital. Portanto, reduzir o seu valor é uma das maneiras mais efetivas para se aumentar o valor das empresas (COPELAND, 1995).

Uma das variáveis que influencia o custo de capital para uma empresa é a dimensão do risco do país em que ela opera e que é percebido pelos investidores internacionais (BODNAR, 2002) como resultado de questões políticas, cambiais e de impostos, entre outras (ZENNER, 2002). Portanto, o custo de capital para as empresas sediadas ou executando projetos em um país deve ser influenciado pelo seu ambiente social, econômico, político, legal e cultural.

Este artigo busca, então, associar a competitividade dos países expressa pelo ranking do IMD, com o valor das empresas e o custo de capital nos países correspondentes. $\mathrm{Na}$ etapa a seguir, está descrita a metodologia dos testes estatísticos, que é seguida pelos resultados e conclusões com as indicações para as futuras pesquisas.

\section{METODOLOGIA}

Em função da existência de uma literatura bastante avançada sobre o tema, a pesquisa caracteriza-se como descritiva, apoiando-se em modelos já construídos sobre o assunto. Quanto aos meios, a pesquisa pode ser considerada como documental, pois se baseou em informações obtidas por meio de levantamentos de dados quantitativos e qualitativos, como os rankings anuais de competitividade produzidos pelo IMD e o WEF.

Os testes estatísticos foram efetuados em quatro etapas. Na primeira, com base nos relatórios anuais do IMD, incluíram-se 44 países desenvolvidos e emergentes; na segunda, foram incluídos somente os 23 países con- siderados como emergentes e que estavam presentes na amostra anterior; na terceira, foram considerados os 21 países desenvolvidos presentes na primeira amostra e na quarta, apenas os seis países da América Latina presentes nos mesmos relatórios. Cada etapa se dividiu em duas partes, cada uma delas utilizando uma diferente variável dependente: o valor das empresas de capital aberto ou o custo de capital nos países correspondentes. Nas regressões, considerando o valor das empresas como variável dependente, o custo de capital foi, também, considerado como uma das variáveis independentes. A lista dos países, junto com a sua posição nos Rankings Gerais de Compe- 
titividade correspondentes aos anos de 2003 e 2004, está no Apêndice.

Como proxy da variável "valor das empresas", utilizouse a razão Valor das Empresas/Valor Contábil (P/V), do dia 30 de junho dos anos de 1996 até 2003. Esse valor é calculado pelo Banco Morgan Stanley para diversos países, com base nos preços das ações das companhias abertas e nos seus correspondentes valores contábeis. Maiores detalhes a respeito da metodologia do cálculo desse índice podem ser obtidos no site: <www.msci.com>.

Para o custo de capital, tanto quando utilizado como variável dependente como independente, usaram-se os resultados dos próprios relatórios do IMD, que o inclui como uma das 77 variáveis que formam o fator Eficiência Governamental. Embora possa se mencionar que há uma certa "circularidade" ao se considerar o custo de capital como uma variável dependente dos fatores de competitividade, uma vez que ele é um dos critérios utilizados para calcular o ranking dos países em relação ao fator Eficiência Governamental, que por sua vez é utilizada para calcular o ranking da Competitividade Geral dos países, considerouse esse efeito diluído por ser ele apenas um entre os 77 critérios que formam o mencionado fator.

Para os dados correspondentes à Competitividade dos países, utilizaram-se cinco variáveis, as seguir descritas:

- Competitividade Geral: É o resultado final do ranking de competitividade das nações, efetuado pelo IMD, baseando-se em quatro variáveis, doravante chamadas de " 4 fatores", que são: Desempenho da Economia, Eficiência do Governo, Ambiente de Negócios e Infra-estrutura. Cada um desses quatro fatores divide-se em outros cinco subfatores, que serão descritos a seguir. No total, há 323 critérios incluídos nesses 4 fatores e que buscam traduzir o conceito de competitividade das nações em um índice que permita compará-las entre si. Para maiores detalhes da metodologia do ranking do IMD, bem como da descrição completa dos critérios de medição da competitividade das nações, consultar o site: < www02. imd.ch/wcc/>. Os quatro fatores que formam a variável Competitividade Geral são descritos a seguir:

- Desempenho da Economia (83 critérios): Esse fator se associa à avaliação macroeconômica da economia doméstica, considerando os subfatores: economia doméstica, comércio internacional, investimentos internacionais, emprego e preços.

- Eficiência do Governo (77 critérios): Busca traduzir se as políticas governamentais procuram levar o país para uma maior competitividade, considerando os subfatores: finanças públicas, políticas fiscais, estruturas institucionais, legislação de negócios e estruturas sociais.

- Ambiente de Negócios (69 critérios): Esse fator procura traduzir em que extensão as empresas que estão competindo são inovadoras, rentáveis e responsáveis socialmente. Inclui como subfatores: produtividade, mercado de trabalho, finanças, práticas gerenciais e atitudes e valores do país.

- Infra-estrutura (94 critérios): Extensão em que as infra-estruturas básica, tecnológica, científica e de recursos humanos atendem às necessidades das empresas, compondo-se dos subfatores: infra-estrutura básica, infra-estrutura tecnológica, infra-estrutura científica, saúde e meio-ambiente e educação.

Foram, então, ajustados os dados dos relatórios anuais do IMD aos dados correspondentes ao valor das empresas do $\mathrm{MSCl}$, uma vez que aqueles se referem às avaliações associadas aos anos anteriores aos de sua publicação. Seguiu-se uma reordenação dos resultados dos rankings de Competitividade Geral, dos 4 fatores e do custo de capital, alterando-se as ordem das escalas, pois nos relatórios do IMD, o país mais competitivo recebe um índice "1", enquanto o menos competitivo recebe um índice " 44 ", na amostra. Assim, o país mais competitivo em um dos fatores passou a receber o índice 44 e o menos competitivo, o índice "1". Dessa maneira, esperava-se encontrar correlações positivas entre as variáveis independentes e dependentes, como indicado pelas fórmulas a seguir, para cada uma das duas partes:

Primeira parte: Valor das Empresas (P/N) como variável dependente:

$$
\mathrm{P} / \mathrm{V}=\gamma+\beta_{1} \text { CompGer }
$$

$$
\begin{gathered}
\mathrm{P} / \mathrm{V}=\gamma+\beta_{1} \text { Econ }+\beta_{2} \text { EfGov }+\beta_{3} \mathrm{Amb}+\beta_{4} \text { Infra } \\
\mathrm{P} / \mathrm{V}=\beta_{1} \text { Cap }
\end{gathered}
$$

Segunda parte: Custo de capital (Cap) como variável dependente:

$$
\text { Cap }=\gamma+\beta_{1} \text { CompGer }
$$

$$
\mathrm{Cap}=\gamma+\beta_{1} \mathrm{Econ}+\beta_{2} \mathrm{EfGov}+\beta_{2} \mathrm{Amb}+\beta_{4} \text { Infra }
$$

Em que: $P / V$ é a razão preço das ações/valor contábil das ações das companhias abertas dos países, fornecido pelo MSCl; CompGer é o índice de Competitividade Geral; Econ corresponde aos resultados do fator Desempenho da Economia; EfGou aos resultados da Eficiência do Governo; Amb ao Ambiente de Negócios; Infra é o fator Infra-estrutura e Cap é o custo de capital.

Os dados foram, então, tratados por meio de uma análise cross sectional dos países, através de regressões lineares. Esperava-se que todos os coeficientes i apresentassem valores positivos. Os resultados estão indicados nas Tabelas I até VIII do Apêndice e descritos na seção seguinte. 


\section{RESULTADOS}

A seguir são descritos os resultados das quatro etapas dos testes estatísticos, cada uma delas utilizando uma variável dependente: o valor das empresas ou o custo de capital do país.

\subsection{Primeira etapa: todos os 44 países da amostra}

As regressões efetuadas considerando o valor das empresas através de sua proxy, valor de mercado/valor contábil, $\mathrm{P} / \mathrm{N}$, como variável dependente e usando como variáveis independentes os resultados dos fatores de competitividade e do custo de capital para todos os 44 países da amostra durante os anos de 1996 a 2003, correspondentes aos relatórios anuais do IMD de 1997 até 2004, mostrou um baixo poder explanatório para o modelo, com o R2 ajustado situado entre os valores de 0,10 a 0,15, como indicado na Tabela 1.

O uso de variáveis dummy correspondentes ao tipo de país, se emergente ou desenvolvido, permitiu melhorar, ainda que marginalmente, o poder explanatório do modelo. Isso se verificou pelos resultados do R2 ajustado para as regressões univariadas tanto com o uso do custo de capital como da Competitividade Geral, como variáveis dependentes, como mostrado nas regressões de (1) a (4) da Tabela 1. Foi observado um efeito de multicolinearidade ocasionado pelo inter-relacionamento entre os quatro fatores considerados como variáveis dependentes: Desempenho da Economia, Eficiência do Governo, Ambiente de Negócios e Infra-estrutura, nas regressões (5) e (6).

$O$ valor das empresas estava significativamente relacionado ao custo de capital dos países da amostra, ao nível de $1 \%$, como verificado pela regressão (1). $A$ inclusão da variável dummy de país reduziu a importância do custo de capital para explicar o valor das empresas, mas conservou a significância estatística da relação em $1 \%$, como pode ser observado pela regressão (4). Observou-se que o valor das empresas, também, se relacionou significativamente com a Competitividade Geral dos países, como esperado, sendo esse impacto novamente menor quando se incluiu a variável dummy de país, ainda ao nível de significância de $1 \%$.

A obtenção de conclusões a partir da utilização conjunta dos quatro fatores como variáveis dependentes é prejudicada devido ao efeito de multicolinearidade verificado nas regressões (5) e (6). Ao analisar conjuntamente os fatores: Ambiente de Negócios e Infra-estrutura observouse uma maior influência daquele no valor das empresas, como indicado em (7).

Ao regredir a variável correspondente ao valor das empresas em relação a cada um dos quatro fatores, separadamente, observou-se que os fatores que exerciam a maior influência no valor das empresas eram o Ambiente de Negócios e a Infra-estrutura, como se observou nas regressões (10) e (11). A Eficiência Governamental seguiu em importância (regressão (9)), seguida pelo Desempenho da Economia, como indicado na coluna (8).
Ao considerar o custo de capital obtido pelos dados dos relatórios anuais do IMD como uma variável dependente e os resultados da competitividade geral dos 44 países como variáveis independentes, verificou-se um melhor poder explanatório das regressões, com o R2 ajustado situando-se entre 0,36 e 0,46, como demonstrado na Tabela 2 .

Novamente, observou-se que o efeito do uso de variáveis dummy correspondentes ao tipo de país, se emergente ou desenvolvido, permitiu melhorar o poder explanatório do modelo, como se observou pelos resultados de R2 ajustado, tanto para as regressões univariadas com o uso da Competitividade Geral como variável dependente (ver as regressões (1) e (2) da Tabela 2), como para as multivariadas, como indicado nas regressões (3) e (4).

As regressões mostraram uma influência significativa, ao nível de 1\%, da Competitividade Geral no custo de capital dos 44 países considerados no período de 1996 até 2003, como indicado nas regressões (1) e (2) da Tabela 2. Nas regressões (3) e (4), ao considerar o conjunto dos quatro fatores, observou-se que a variável "Infra-estrutura" era a que possuía a maior influência sobre o custo de capital, seguida pela Eficiência Governamental, significativas a 1\%. O Desempenho da Economia possuía um relacionamento significativo estatisticamente a $5 \%$ e $10 \%$, dependendo se eram consideradas ou não as variáveis dummy de país. $\mathrm{O}$ Ambiente de Negócios não se mostrou relacionado de maneira estatisticamente significante com o custo de capital.

Ao considerar os quatro fatores em separado, as regressões indicaram que todos eles se relacionavam positiva e significativamente ao nível de $1 \%$ com o custo de capital dos países, sendo a maior influência proveniente da Infra-estrutura, seguida pelo Ambiente de Negócios e pela Eficiência Governamental, que apresentaram coeficientes muito próximos, e, finalmente, pelo fator Desempenho da Economia.

\subsection{Segunda etapa: amostra de $\mathbf{2 3}$ paises emergentes}

As regressões efetuadas considerando o valor das empresas dos países emergentes, através de sua proxy, valor de mercado/valor contábil, P/N, como variável dependente e usando como variáveis independentes os resultados de competitividade e o custo de capital para os 23 países emergentes apresentou um baixo poder explanatório do modelo, com o R2 ajustado se situando entre os valores de $-0,03$ a 0,06, como indicado na Tabela 3.

Além disso, observou-se, novamente, um efeito de multicolinearidade ocasionado pelo inter-relacionamento entre os quatro fatores quando considerados como variáveis dependentes conjuntamente: Desempenho da Economia, Eficiência do Governo, Ambiente de Negócios e Infraestrutura, como foi observado na regressão (3).

O custo de capital não apresentou um relacionamento estatisticamente significativo com o valor das empresas dos países emergentes, como indicado na regressão (1). 
No entanto, a Competitividade Geral relacionou-se com o valor das empresas dos países emergentes da amostra ao nível de $10 \%$ (regressão (2)). Ao considerar os fatores em separado, como indicado nas regressões de (4) até (7), observou-se que o fator Ambiente de Negócios possuía a maior influência sobre o valor das empresas, bem como a mais relevante significância estatística, quando considerados os demais três fatores. Os demais três fatores apresentaram pouca influência sobre o valor das empresas de países emergentes, bem como ausência de significância estatística.

Ao considerar o custo de capital dos relatórios anuais do IMD como uma variável dependente e os resultados da competitividade geral dos 23 países emergentes como variáveis independentes, verificou-se um maior poder explanatório para as regressões, com o R2 ajustado situando-se entre 0,11 e 0,26, como indicado na Tabela 4.

A Competitividade Geral dos países relacionou-se positiva e significativamente ao nível de $1 \%$ com o custo de capital dos países emergentes, como indicado pela regressão (1). Ao regredir o custo de capital com os 4 fatores em conjunto, observou-se a maior influência da variável Eficiência do Governo, significativa ao nível de $1 \%$ e a Infra-estrutura, ao nível de 10\%, como indicado na regressão (2).

Quando se consideraram os quatro fatores em separado, todos se mostraram relacionados positivamente com o custo de capital com uma significância estatística de 1\%, sendo verificadas as relações mais fortes, pela ordem, com: a Eficiência Governamental, Ambiente de Negócios, Infraestrutura e o Desempenho da Economia, como indicado nas regressões de (3) a (6).

\subsection{Terceira etapa: amostra de 21 países desenvolvidos}

As regressões efetuadas considerando os valores das empresas dos países desenvolvidos, através de sua proxy, valor de mercado/valor contábil, P/V, como variável dependente e usando como variáveis independentes os resultados de competitividade e o custo de capital relacionado para os 21 países desenvolvidos, apresentou um limitado poder explanatório do modelo, com o R2 ajustado situando-se entre os valores de 0,017 a 0,135, como indicado na Tabela 5

Além disso, observou-se, novamente, um efeito de multicolinearidade ocasionado pelo inter-relacionamento entre os quatro fatores quando considerados como variáveis dependentes conjuntamente: Desempenho da Economia, Eficiência do Governo, Ambiente de Negócios e Infraestrutura, como foi observado na regressão (3).

Tanto o custo de capital como a Competitividade Geral apresentaram um relacionamento estatisticamente significativo com o valor das empresas dos países desenvolvidos, como indicado nas regressões (1) e (2). Ao considerar os fatores em separado, como indicado nas regressões de (4) até (7), observou-se que o fator Infra-estrutura possuía a maior influência sobre o valor das empresas, bem como a mais relevante significância estatística, seguida pelos fato- res Ambiente de Negócios, Eficiência do Governo e Desempenho da Economia.

Ao considerar o custo de capital dos relatórios anuais do IMD como uma variável dependente e os resultados da competitividade geral dos 23 países emergentes como variáveis independentes, verificou-se, ainda, um reduzido poder explanatório para as regressões, com o R2 ajustado situando-se entre 0,02 e 0,17, como indicado na Tabela 6 .

A Competitividade Geral dos países relacionou-se positiva e significativamente ao nível de $1 \%$ com o custo de capital dos países emergentes, como indicado pela regressão (1). Ao regredir o custo de capital com os quatro fatores em conjunto, observou-se uma maior influência exercida pela variável Infra-estrutura, significativa ao nível de 5\% e a Eficiência do Governo, ao nível de 1\%, como indicado na regressão (2).

Quando se consideraram os quatro fatores em separado, todos se mostraram relacionados positivamente com o custo de capital e de maneira estatisticamente significante, sendo verificadas as relações mais fortes, pela ordem, com: a Infra-estrutura, Ambiente de Negócios, Eficiência Governamental (todos a 1\%), e o Desempenho da Economia (a $5 \%$ ), como indicado nas regressões de (3) a (6).

\subsection{Quarta etapa: amostra de 6 países da América Latina}

As regressões calculadas considerando o valor das empresas dos países da América Latina como variável dependente e usando como variáveis independentes os resultados de competitividade e o custo de capital, demonstrou um baixo poder explanatório do modelo, com o R2 ajustado possuindo valores variando de $-0,07$ a 0,2 , como indicado na Tabela 5.

Além disso, observou-se, novamente, um efeito de multicolinearidade ocasionado pelo inter-relacionamento entre os quatro fatores, quando considerados como variáveis dependentes conjuntamente: Desempenho da Economia, Eficiência do Governo, Ambiente de Negócios e Infra-estrutura, como pode ser observado nas regressões (3) e (8).

Ao considerar os fatores em separado, como indicado nas regressões de (4) até (7), observou-se que o fator Desempenho da Economia possuía a maior influência sobre o valor das empresas, bem como a mais relevante significância estatística, quando considerados os demais três fatores. O segundo fator mais importante foi a Eficiência Governamental, seguida pelo Ambiente de Negócios. Diferentemente do esperado, o fator Infra-estrutura relacionou-se negativamente com o valor das empresas.

Ao considerar o custo de capital dos relatórios anuais do IMD como uma variável dependente e os resultados dos rankings de competitividade dos seis países da América Latina como variáveis independentes, verificou-se, novamente, um limitado poder explanatório para as regressões, com o R2 ajustado situando-se entre -0,01 e 0,08, como indicado na Tabela 6.

Além disso, observou-se um efeito de multicolinearidade ocasionado pelo inter-relacionamento entre os quatro 
fatores, tomados como variáveis dependentes conjuntamente: Desempenho da Economia, Eficiência do Governo, Ambiente de Negócios e Infra-estrutura, como pôde ser observado na regressão (2).

A Competitividade Geral dos países relacionou-se positiva e significativamente ao nível de $5 \%$ com o custo de capital dos países latino-americanos da amostra, como indicado pela regressão (1). Quando se consideraram os quatro fatores em separado, apenas a Eficiência Governamental e o Ambiente de Negócios apresentaram um relacionamento significativo ao nível de $5 \%$ com o custo de capital, como indicado nas regressões (4) e (5).

\section{DISCUSSÃO DOS RESULTADOS}

O estudo possui algumas limitações. Em primeiro lugar, em análises do tipo cross sectional, como as que foram efetuadas, as variáveis independentes podem sofrer influências diferentes de acordo com o país ou região pertencente às amostras. Para buscar compensar essa limitação, efetuaram-se testes estatísticos com quatro grupos em separado: os 44 países presentes na amostra do $\mathrm{MSCl}$ e do IMD, os 23 países considerados como emergentes, os demais 21 países desenvolvidos presentes e os seis países da América Latina.

Uma outra limitação seria a existência de uma associação entre o valor das empresas de um país com as suas oportunidades de crescimento futuro, o que seria captado pelos dados do $\mathrm{MSCl}$. Já o ranking do IMD, possui predominantemente critérios estáticos.

A terceira limitação seria a existência de uma proporção importante de empresas de capital fechado nos países emergentes e na América Latina, em relação aos países desenvolvidos. Isso pode ter reduzido a significância dos relacionamentos encontrados entre o ambiente competitivo desses países com o valor dessas empresas, que não é capturado pelo $\mathrm{MSCl}$, que acompanha apenas o valor das companhias abertas.

O valor das empresas da amostra completa de 44 países apresentou uma forte associação com a Competitividade Geral dos países, embora essa relação não fosse tão robusta ao se considerarem amostras menores, como a dos países desenvolvidos, emergentes ou os países da América Latina. Mais pesquisa seria necessária para verificar as explicações para a redução dessa significância estatística que não estivessem associadas ao menor tamanho das amostras.

A relação entre o valor das empresas e o custo de capital foi confirmada tanto na amostra de todos os 44 países, como na amostra dos países desenvolvidos. Esse resultado pode indicar que, mesmo diante de elevados valores para o custo de capital, as empresas de países emergentes ainda podem adicionar valor para os seus acionistas.

Em geral, o fator mais associado ao valor das empresas é o Ambiente de Negócios, demonstrando a importância que variáveis como a produtividade, as características do mercado de trabalho, das finanças locais, das práticas gerenciais e mesmo das principais atitudes e valores no país, possuem para aumentar o valor das companhias abertas das nações.

No entanto, para os países desenvolvidos, a variável mais importante para influenciar o valor das empresas foi a Infra-estrutura, o que destaca a relevância das infra-es- truturas básica, tecnológica, científica e de recursos humanos para incentivar o dinamismo das empresas localizadas nesses países. Esse resultado deve se associar ao tipo das indústrias presentes nesses países, mais voltadas para a inovação e ao valor adicionado para os seus produtos, ou destinadas a consumidores mais sofisticados.

Um resultado interessante ocorreu com a menor influência observada para os fatores Desempenho da Economia e Eficiência do Governo no valor das empresas ao se considerar tanto a amostra completa de 44 países como a dos países desenvolvidos. A menor importância do Desempenho da Economia pode indicar uma espécie de "convergência" entre as políticas e resultados macroeconômicos dos diversos países, o que tornaria as questões microeconômicas mais relevantes para a criação de valor pelas empresas à medida que os países se desenvolvem.

No entanto, para a amostra dos seis países da América Latina presentes nos estudos do IMD, os resultados indicam que, para a América Latina, ao contrário dos resultados obtidos ao serem considerados todos os 44 países da amostra ou mesmo os países desenvolvidos, o Desempenho da Economia é um fator relevante para a criação e sustentação de valor para as empresas, ou seja, o valor das empresas, nessa região, ainda se associa ao crescimento da economia como um todo, aos níveis de poupança e investimento, ao equilíbrio das balanças comerciais, à atração dos investimentos externos, ao nível de empregos e preços na economia. O segundo fator em importância é a Eficiência Governamental, o que mostra a relevância, para esses países, do adequado gerenciamento das finanças públicas e das políticas fiscais, de uma legislação moderna e aplicada eficientemente quando necessária, além de instituições políticas e públicas transparentes, honestas e eficientes na região.

Os resultados parecem indicar a maior importância que os fatores Desempenho da Economia e Eficiência Governamental possuem para aumentar o valor das empresas em países emergentes, em comparação com os países desenvolvidos. À medida que os países alcançassem maiores níveis de desenvolvimento, outras variáveis adquiririam maior importância, como o Ambiente dos Negócios e a Infra-estrutura.

Os resultados gerais apontaram a Eficiência Governamental como o fator mais fortemente associado ao custo de capital. Isso parece indicar que os investidores irão requerer maiores retornos, o que é semelhante a elevar o custo de capital, nos países em que a Eficiência Governamental seja menor, ou seja, nos países que não disponham 
de um adequado gerenciamento de suas finanças públicas e de suas políticas fiscais, bem como de uma legislação moderna para os negócios e que seja aplicada eficientemente quando necessária, além de instituições políticas e públicas transparentes, honestas e eficientes.

Para a amostra dos países desenvolvidos, o fator mais fortemente relacionado ao Custo de Capital foi a Infraestrutura. Isso pode indicar que, em países nos quais a Infra-estrutura seja deficiente, as empresas podem dispor de custos de capital mais elevados quando elas precisarem incorrer em custos para compensar ineficiências dos países em áreas como educação e infra-estrutura básica como estradas, aeroportos, energia e comunicações, ou mesmo mais sofisticadas como tecnológica e científica. A Competitividade Geral, também, confirmou seu relacionamento com o custo de capital, embora essa relação tenha sido menos robusta na amostra dos países latino-americanos.

\section{CONCLUSÕES}

Os resultados da pesquisa permitem concluir pela importância do ambiente competitivo nacional para explicar as diferenças de valor entre as empresas e do custo de capital entre os países. Os resultados indicaram, também, que o ambiente competitivo influencia mais o custo de capital do que o valor das empresas. Isso pode indicar que o valor das empresas é mais afetado pelo seu ambiente mais próximo, por variáveis como a dinâmica das indústrias em que elas operam ou mesmo o seu posicionamento competitivo em seus mercados.

O estudo mostra a relevância de uma agenda ativa para os países que buscam aumentar a capacidade de criação de riquezas pelas suas empresas. Especificamente para a América Latina, apesar dos progressos no campo das fi- nanças públicas e com as políticas fiscais, ainda há muitas reformas necessárias ou que estão incompletas e que precisam enfocar a capacidade de criação de um ambiente que permita às empresas da região serem competitivas no longo prazo.

Futuras pesquisas poderiam utilizar dados de custo de capital de outras fontes de informações, testar uma maior quantidade de critérios como variáveis independentes em relação ao valor das empresas e do custo de capital nos países ou mesmo utilizar uma série mais longa de dados. Outros rankings de competitividade produzidos por outras instituições também poderiam ser adotados para comparação com os do IMD.

\section{Referências Bibliográficas}

BEIM, D.; CALOMIRIS, C.. Emerging Financial Markets. New York: McGraw-Hill/Irwin, 2001.

BARNEY, J.B.. Gaining and Sustaining Competitive Advantage. Upper Saddle River: Addison-Wesley, 1996.

BODNAR, G.; DUMAS, B.; MARSTON, R.. Cross-Border Valuation: The International Cost of Equity Capital. In: VALUATION IN EMERGING MARKETS, 2002, Virginia: The Darden School-University of Virginia, 2002.

COPELAND, T.; KOLLER, T.; MURRIN, J.. Valuation: Measuring and Managing the Value of Companies. Hoboken: J. Wiley, 1995.

THE WORLD COMPETITIVENESS YEARBOOK 2004. Lauzane: Institute for Management Development, 2004.

DAMODARAN, A.. The Dark Side of Valuation. New Jersey: Financial Times-Prentice Hall, 2001.

DRUCKER, P.. The Age of Discontinuity. Somerset: Transaction Publishers, 1969.

FISHER, F.; McGOWAN, J.. On the Misuse of Accounting Rates of Return to Infer Monopoly Profits. American Economy Review, v.73, p.82-97, 1983.

JOSE, M.L.; NICHOLS, L.M.; STEVENS, J.L.. Contributions of Diversification, Promotion and R\&D to the value of Multiproduct Firms: A Tobin's q Approach. Financial Management, p.33-42, winter 1986.

KLAPPER, L.; LOVE, I.. Corporate Governance, Investor Protection and Performance in Emerging Markets, In: VALUATION IN EMERGING MARKETS, 2002, Virginia: The Darden School-University of Virginia, 2002.

KOGUT, B.. Country capabilities and the permeability of borders, Strategic Management Journal, v.12, p. 33-47, 1991.

LA PORTA, R.; LOPEZ-DE-SILANES, F.; SCHLEITER, A.; VISHNY, R.. Legal Determinants of External Finance. Journal of Finance, v.52, p.137-181,1997.

The quality of government. The Journal of Law, Economics and Organization, v.15, p.222-279, 1999.

LEE, C.; NG, D.. Corruption and International Valuation: Does Virtue Pay? In: VALUATION IN EMERGING MARKETS, 2002, Virginia: The Darden School-University of Virginia, 2002.

LINDENBERG, E.; ROSS, S.. Tobin's q Ratio and Industrial Organization. Journal of Business, v.54, n.1, p.1-32, 1981.

MARX, K.. Capital: A Critique of Political Economy. London: Penguin Books, 1976.

NEGROPONTE, N.. Being Digital. New York: Vintage Books, 1995. 
PORTER, M.. Competitive Advantage. New York: The Free Press, 1980.

The Competitive Advantage of Nations. New York: The Free Press, 1990.

PETERAF, M.A.. The cornerstones of competitive advantage: a resource-based view. Strategic Management Journal, v.14, p.179-191, 1993. RICARDO, D.. Principles of Political Economy and Taxation. Amherst: Prometheus Books, 1996.

SCHUMPETER, J.A.. Capitalismo, Socialismo e Democracia. Rio de Janeiro: Zahar, 1984.

SLOAN, A.. My Years with General Motors. New York: Doubleday, 1963.

SMIRLOCK, M.; GILLIGAN, T.; MARSHALL, W.. Tobin's q and the Structure-Performance Relationship. American Economic Review. V.74, p.1051-1060, 1984.

SMITH, A.. The Wealth of Nations. New York: The Modern Library, 2000.

TOBIN, J.. A General Equilibrium Approach to Monetary Theory. Journal of Money Credit and Banking, v.1, p.15-29, 1969.

VILLALONGA, B.. Intangible resources, Tobin's q, and sustainability of performance differences. Journal of Economic Behavior \& Organization, v.54, n.2, p.205-230, 2004.

WEBER, M.. The Protestant Ethic and the Spirit of Capitalism. Londres: Routledge Classics, 2001.

THE GLOBAL COMPETITIVENESS REPORT 2000 - WORLD ECONOMIC FORUM. Nova Iorque: Oxford University Press, 2000.

WERNERFELT, B.. A resource-based view of the firm. Strategic Management Journal, v.5, p.171-180, 1984.

ZENNER, M.; AKAYDIN, E.. A Practical Approach to the International Valuation and Capital Allocation Puzzle. In: VALUATION IN EMERGING MARKETS, 2002. Virginia: The Darden School-University of Virginia, 2002.

\section{NOTA - Endereço dos autores}

PUC-Rio de Janeiro

Depto. de Administração

Rua Marquês de São Vicente, 225 - prédio IAG - Gávea

Rio de Janeiro - RJ

22.453-900 
APÊNDICE

Lista dos países e a posição no Ranking de Competitividade do IMD em 2003 e 2004

\begin{tabular}{|c|c|c|}
\hline País & Ranking 2003 & Ranking 2004 \\
\hline África do Sul & 47 & 49 \\
\hline Alemanha & 21 & 21 \\
\hline Argentina & 58 & 60 \\
\hline Austrália & 7 & 4 \\
\hline Áustria & 14 & 13 \\
\hline Bélgica & 18 & 25 \\
\hline Brasil & 52 & 53 \\
\hline Canadá & 6 & 3 \\
\hline Chile & 26 & 26 \\
\hline China & 29 & 24 \\
\hline Colômbia & 45 & 41 \\
\hline Coréia do Sul & 37 & 35 \\
\hline Dinamarca & 5 & 7 \\
\hline Espanha & 27 & 31 \\
\hline Estados Unidos & 1 & 1 \\
\hline Filipinas & 49 & 52 \\
\hline Finlândia & 3 & 8 \\
\hline França & 23 & 30 \\
\hline Grécia & 42 & 44 \\
\hline Holanda & 13 & 15 \\
\hline Hong Kong & 10 & 5 \\
\hline Hungria & 34 & 41 \\
\hline Índia & 50 & 34 \\
\hline Indonésia & 57 & 58 \\
\hline Irlanda & 11 & 10 \\
\hline Israel & 33 & 33 \\
\hline Itália & 41 & 51 \\
\hline Japão & 25 & 23 \\
\hline Malásia & 21 & 16 \\
\hline México & 53 & 56 \\
\hline Noruega & 15 & 17 \\
\hline Nova Zelândia & 16 & 18 \\
\hline Polônia & 55 & 57 \\
\hline Portugal & 39 & 39 \\
\hline Reino Unido & 19 & 22 \\
\hline República Tcheca & 35 & 43 \\
\hline Rússia & 54 & 50 \\
\hline Singapura & 4 & 2 \\
\hline Suécia & 12 & 11 \\
\hline Suíça & 9 & 14 \\
\hline Tailândia & 30 & 29 \\
\hline Taiwan & 17 & 12 \\
\hline Turquia & 56 & 55 \\
\hline Venezuela & 59 & 60 \\
\hline
\end{tabular}




\section{TABELAS I A VIII}

A variável dependente nas Tabelas $10,30,50$ e $7 \bullet, \mathrm{P} / \mathrm{N}$, Valor de mercado/Nalor contábil, mede o valor das empresas dos 44 países. A variável dependente nas Tabelas $20,4 \boldsymbol{\bullet}$, $6 \bullet$ e $8 \bullet$, Custo de Capital, foi obtida a partir dos relatórios do IMD. Competitividade Geral é a medida de competitividade produzida pelo IMD a partir dos quatro fatores: Desempenho da Economia, Eficiência do Governo, Ambiente de Negócios e Infra-estrutura. Os dados correspondem aos anos de 1996 até 2003. As regressões incluem uma variável dummy para o tipo de país, se emergente ou desenvolvido. As estatísticas " $t$ " estão entre parênteses. ${ }^{*},{ }^{* *} e^{* * *}$, indicam significância estatística a $1 \%, 5 \%$ e $10 \%$, respectivamente.

Tabela 1 Valor das empresas e competitividade dos países

(1)

\begin{tabular}{|c|c|c|c|c|c|c|c|c|c|c|c|}
\hline Competitividade geral & & $\begin{array}{c}0,346 \\
(6,874)^{*}\end{array}$ & \begin{tabular}{|c}
0,234 \\
$(3,396)^{*}$ \\
\end{tabular} & & & & & & & & \\
\hline $\begin{array}{l}\text { Desempenho } \\
\text { da economia }\end{array}$ & & & & & $\begin{array}{l}0,08 \\
(0,122)\end{array}$ & $\begin{array}{l}-0,023 \\
(-0,344)\end{array}$ & & $\begin{array}{c}0,088 \\
(1,421) \\
\star * \star\end{array}$ & & & \\
\hline Eficiência do governo & & & & & $\begin{array}{l}-0,203 \\
(-2,079)\end{array}$ & & & & $\begin{array}{c}0,122 \\
(2,033) \\
\star *\end{array}$ & & \\
\hline Ambiente de negócios & & & & & $\begin{array}{c}0,366 \\
(3,389)^{*}\end{array}$ & $\begin{array}{c}0,219 \\
(2,67)^{\star}\end{array}$ & $\begin{array}{c}0,212 \\
(2,667)^{*}\end{array}$ & & & $\begin{array}{c}0,255 \\
(4,219)^{*}\end{array}$ & \\
\hline Infra-estrutura & & & & & $\begin{array}{c}0,094 \\
(0,976)\end{array}$ & $\begin{array}{c}0,085 \\
(0,876) \\
\end{array}$ & $\begin{array}{c}0,081 \\
(0,839) \\
\end{array}$ & & & & $\begin{array}{c}0,247 \\
(3,343)^{*}\end{array}$ \\
\hline Custo de capital & $\begin{array}{c}0,353 \\
(7,056)^{*}\end{array}$ & & & $\begin{array}{c}0,250 \\
(4,187)^{*}\end{array}$ & & & & & & & \\
\hline Dummy país & Não & Não & Sim & $\operatorname{sim}$ & Sim & Sim & Sim & $\operatorname{sim}$ & Sim & Sim & $\operatorname{sim}$ \\
\hline R2 ajustado & 0,122 & 0,117 & 0,129 & 0,143 & 0,149 & 0,141 & 0,143 & 0,105 & 0,110 & 0,143 & 0,128 \\
\hline
\end{tabular}

Tabela 2 ॥ Custo de Capital e competitividade dos países

(1)

\begin{tabular}{|c|c|c|c|c|c|c|c|c|}
\hline Competitividade geral & $\begin{array}{c}0,671 \\
(16,872)^{\star}\end{array}$ & $\begin{array}{c}0,543 \\
(10,063)^{*} \\
\end{array}$ & & & & & & \\
\hline $\begin{array}{l}\text { Desempenho } \\
\text { da economia }\end{array}$ & & & $\begin{array}{l}0,116 \\
(2,189)^{\star *}\end{array}$ & $\begin{array}{c}0,081 \\
(1,509)^{\star * *}\end{array}$ & $\begin{array}{c}0,283 \\
(5,439)^{\star}\end{array}$ & & & \\
\hline Eficiência do governo & & & $\begin{array}{c}0,214 \\
(2,731)^{\star}\end{array}$ & $\begin{array}{c}0,214 \\
(2,766)^{\star}\end{array}$ & & $\begin{array}{c}0,426 \\
(8,958)^{*}\end{array}$ & & \\
\hline Ambiente de negócios & & & $\begin{array}{c}0,094 \\
(1,038)\end{array}$ & $\begin{array}{c}0,103 \\
(1,207) \\
\end{array}$ & & & $\begin{array}{c}0,429 \\
(8,715)^{*}\end{array}$ & \\
\hline Infra-estrutura & & & $\begin{array}{c}0,338 \\
(5,074)^{\star}\end{array}$ & $\begin{array}{l}0,223 \\
(2,912)^{\star}\end{array}$ & & & & $\begin{array}{c}0,484 \\
(8,029)^{\star}\end{array}$ \\
\hline Dummy país & Não & Sim & Não & Sim & Sim & Sim & Sim & Sim \\
\hline R2 ajustado & 0,448 & 0,465 & 0,453 & 0,465 & 0,363 & 0,439 & 0,433 & 0,417 \\
\hline
\end{tabular}


Tabela 3 Valor das empresas e competitividade dos países emergentes

(1)

$$
\text { (2) }
$$

(3)

\begin{tabular}{|c|c|c|c|c|c|c|c|}
\hline Competitividade geral & & $\begin{array}{l}0,101 \\
(1,357)^{\star * *}\end{array}$ & & & & & \\
\hline $\begin{array}{l}\text { Desempenho } \\
\text { da economia }\end{array}$ & & & $\begin{array}{c}0,097 \\
(0,983)\end{array}$ & $\begin{array}{c}0,054 \\
(0,731)\end{array}$ & & & \\
\hline Eficiência do governo & & & $\begin{array}{c}-0,322 \\
(-2,251)\end{array}$ & & $\begin{array}{c}0,067 \\
(0,896)\end{array}$ & & \\
\hline Ambiente de negócios & & & $\begin{array}{c}0,534 \\
(3,944)^{*}\end{array}$ & & & $\begin{array}{c}0,209 \\
(2,871)^{\star}\end{array}$ & \\
\hline Infra-estrutura & & & $\begin{array}{c}-0,162 \\
(-1,580)\end{array}$ & & & & $\begin{array}{c}0,061 \\
(0,825) \\
\end{array}$ \\
\hline Custo de capital & $\begin{array}{r}0,072 \\
(-0,968) \\
\end{array}$ & & & & & & \\
\hline R2 ajustado & 0,000 & 0,050 & 0,065 & $-0,030$ & $-0,010$ & 0,038 & $-0,020$ \\
\hline
\end{tabular}

Tabela 4 Custo de Capital e competitividade dos países emergentes
(2)

\begin{tabular}{l|c|c|c|c|c|c} 
Competitividade geral & $\begin{array}{c}0,512 \\
(8,000)^{*}\end{array}$ & & & & & \\
\hline Desempenho & & 0,034 & 0,344 & & & \\
da economia & & $(0,381)$ & $(4,920)^{*}$ & & & \\
\hline Eficiência do governo & & 0,214 & & 0,500 & & \\
\hline Ambiente de negócios & & 0,094 & & & 0,456 & \\
& & $(0,779)$ & & & $(6,874)^{*}$ & \\
\hline Infra-estrutura & & 0,094 & & & & 0,401 \\
& & $(1,360)^{* * *}$ & & & & $(5,881)^{*}$ \\
\hline R2 ajustado & 0,258 & 0,252 & 0,114 & 0,246 & 0,204 & 0,157
\end{tabular}

Tabela 5 Valor das empresas e competitividade dos países desenvolvidos

(1)

\begin{tabular}{|c|c|c|c|c|c|c|c|}
\hline Competitividade geral & & $\begin{array}{c}0,271 \\
(3,617)^{*}\end{array}$ & & & & & \\
\hline $\begin{array}{l}\text { Desempenho } \\
\text { da economia }\end{array}$ & & & $\begin{array}{c}-0,013 \\
(-0,158)\end{array}$ & $\begin{array}{c}0,107 \\
(0,387)\end{array}$ & & & \\
\hline Eficiência do governo & & & $\begin{array}{c}-0,123 \\
(-0,946)\end{array}$ & & $\begin{array}{c}0,151 \\
(1,968)^{\star * *}\end{array}$ & & \\
\hline Ambiente de negócios & & & $\begin{array}{r}0,193 \\
-1,402 \\
\end{array}$ & & & $\begin{array}{c}0,238 \\
(3,142)^{*}\end{array}$ & \\
\hline Infra-estrutura & & & $\begin{array}{c}0,253 \\
(2,771)^{\star *}\end{array}$ & & & & $\begin{array}{c}0,302 \\
(4,064)^{*}\end{array}$ \\
\hline Custo de capital & $\begin{array}{c}0,374 \\
(5,180) *\end{array}$ & & & & & & \\
\hline R2 ajustado & 0,068 & 0,135 & 0,081 & 0,060 & 0,017 & 0,051 & 0,085 \\
\hline
\end{tabular}


Tabela 6 Custo de Capital e competitividade dos países desenvolvidos

(1)

\begin{tabular}{l|c|c|c|c|c|c} 
Competitividade geral & $\begin{array}{c}0,419 \\
(5,934)^{*}\end{array}$ & & & & & \\
\hline Desempenho & & $\begin{array}{c}0,059 \\
(0,754)\end{array}$ & $\begin{array}{c}0,175 \\
(2,283)^{* *}\end{array}$ & & & \\
\hline da economia & & 0,129 & & 0,345 & & \\
\hline Eficiência do governo & & $(1,075)^{*}$ & & $(4,719)^{*}$ & & \\
\hline Ambiente de negócios & & 0,123 & & & 0,379 & \\
& & $(0,942)$ & & & $(5,262)^{*}$ & \\
\hline Infra-estrutura & & 0,239 & & & & 0,386 \\
& & $(2,769)^{* *}$ & & & & $(5,382)^{*}$ \\
\hline R2 ajustado & 0,171 & 0,174 & 0,025 & 0,114 & 0,138 & 0,144
\end{tabular}

Tabela 7 Valor das empresas e competitividade dos países Latino-Americanos

(1)

(2)

(3)

(4)

(5)
(8)

\begin{tabular}{|c|c|c|c|c|c|c|c|c|}
\hline Competitividade geral & & $\begin{array}{l}0,211 \\
(1,447)^{\star \star \star}\end{array}$ & & & & & & \\
\hline $\begin{array}{l}\text { Desempenho } \\
\text { da economia }\end{array}$ & & & $\begin{array}{c}0,483 \\
(2,934) *\end{array}$ & $\begin{array}{c}0,451 \\
(3,392) *\end{array}$ & & & & $\begin{array}{c}0,453 \\
(2,766)^{*}\end{array}$ \\
\hline Eficiência do governo & & & $\begin{array}{l}0,235 \\
(1,102)^{* * *}\end{array}$ & & $\begin{array}{l}0,255 \\
(1,771)^{\star *}\end{array}$ & & & $\begin{array}{c}-0,003 \\
(-0,018)\end{array}$ \\
\hline Ambiente de negócios & & & $\begin{array}{c}-0,221 \\
(-1,076) \\
\end{array}$ & & & $\begin{array}{l}0,121 \\
(0,821)^{\star *}\end{array}$ & & \\
\hline Infra-estrutura & & & $\begin{array}{c}-0,195 \\
(-1,277) \\
\end{array}$ & & & & $\begin{array}{c}-0,069 \\
(-0,461) \\
\end{array}$ & \\
\hline Custo de capital & $\begin{array}{c}0,16 \\
(1,089) \\
\end{array}$ & & & & & & & \\
\hline R2 ajustado & 0,04 & 0,023 & 0,194 & 0,186 & 0,044 & $-0,070$ & $-0,017$ & 0,167 \\
\hline
\end{tabular}

Tabela 8 Custo de Capital e competitividade dos países Latino-Americanos

(1)

\begin{tabular}{l|c|c|c|c|c|c} 
Competitividade geral & $\begin{array}{c}0,275 \\
(1,921)^{\star *}\end{array}$ & & & & & \\
\hline Desempenho & & $\begin{array}{c}-0,156 \\
(-0,871)\end{array}$ & $\begin{array}{c}0,098 \\
(-0,661)\end{array}$ & & & \\
da economia & & 0,241 & & 0,317 & & \\
\hline Eficiência do governo & & $(1,044)$ & & $(2,241)^{\star *}$ & & \\
\hline Ambiente de negócios & & 0,211 & & & 0,315 & \\
& & $(0,943)$ & & & $(2,223)^{\star *}$ & \\
\hline Infra-estrutura & & 0,016 & & & & 0,187 \\
& & $(0,099)$ & & & & $(-1,275)$ \\
\hline R2 ajustado & 0,055 & 0,048 & $-0,012$ & 0,08 & 0,079 & 0,013
\end{tabular}

